\title{
Tinjauan Aktifitas Pasar Tradisional Yang Dipergunakan Masyarakat Dalam Mempengaruhi Kinerja Jalan (Studi Kasus: Pasar Teratai Pontianak)
}

\author{
Ranty Christiana $^{1 *}$, Ika Muthya Anggraini ${ }^{2}$, Hezliana Syahwanti ${ }^{3}$ \\ ${ }^{1,2,3}$ Program Studi Teknik Sipil, Universitas Panca Bhakti, Pontianak \\ *Koresponden email: ranty_christiana @yahoo.co.id
}

Diterima: 26 Januari 2021

Disetujui: 9 Maret 2021

\begin{abstract}
The number of people utilizing the city market facility is likely to increase day by day. It causes the market conditions to become congested. Therefore, it cannot be denied that the existing main roads are definetly affected by this condition. For this reason, the performance of the roads needs to be further reviewed since they are openly accessed by the community also due tothe influence of Teratai Market activities. A descriptive method is used in this studyby surveying the conditions of the Komyos Sudarso road. The calculation is carried out based on the Indonesian Road Capacity Manual (MKJI) 1997. The results of this study shows that the activities of the Teratai Market greatly affect road capacity resulting in the increased of traffic volume. When the market operates, the trafficbecomes denser as such a large number of vehicles are commuting on the road. The observation area is included in a commercial area with high roadside activity as evidenced by a side friction survey which shows a high side friction class count with a weighted frequency of 508.3. The results of the road performance show that Jalan Komyos Sudarso is still not saturated, in which the DS value is 0.34 and the average speed of light vehicles is 42 $\mathrm{km} /$ hour.
\end{abstract}

Keywords: teratai market, road performance, traffic volume, side friction, komyos sudarso road

\begin{abstract}
Abstrak
Masyarakat pengguna pasar semakin hari semakin bertambah banyak jumlahnya, sehingga kondisi pasar menjadi padat dan dapat mempengaruhi kondisi jalan utama yang ada. Untuk itu perlu ditinjau lebih lanjut untuk mengetahui kinerja jalan yang digunakan oleh masyarakat akibat pengaruh aktifitas Pasar Teratai. Metode yang digunakan pada penelitian ini adalah metode deskriptif dengan melakukan survei terhadap kondisi dari jalan Komyos Sudarso. Perhitungan akan dilakukan berdasarkan Manual Kapasitas Jalan Indonesia (MKJI) 1997. Hasil penelitian menunjukkan bahwa aktifitas Pasar Teratai sangat berpengaruh terhadap kapasitas jalan yang mengakibatkan volume lalu lintas menjadi semakin meningkat. Pada saat pasar beroperasi lalu lintas menjadi semakin padat dengan diperolehnya jumlah kendaraan yang begitu besar. Daerah pengamatan termasuk dalam daerah komersial dengan aktifitas sisi jalan yang tinggi yang dibuktikan dengan survei hambatan samping yang menunjukkan hasil hitungan kelas hambatan samping yang tinggi dengan frekuensi bobot 508,3. Untuk hasil dari kinerja jalan menunjukkan Jalan Komyos Sudarso masih belum jenuh dengan nilai DS = 0,34 dan diperoleh kecepatan rata- rata kendaraan ringan yang masih di angka $37 \mathrm{~km} / \mathrm{jam}$.
\end{abstract}

Kata kunci: pasar teratai, kinerja jalan, volume lalu lintas, hambatan samping, jalan komyos sudarso

\section{Pendahuluan}

Berdasarkan Manual Kapasitas Jalan Indonesia yang dikatakan sebagai segmen jalan perkotaan adalah jalan yang mempunyai perkembangan secara permanen dan menerus di sepanjang seluruh atau hampir seluruh jalan, minimum pada satu sisi jalan, apakah berupa perkembangan lahan atau bukan [1]. Kapasitas menurut MKJI 1997 adalah arus lalu lintas maximum yang dapat dipertahankan (tetap) pada suatu bagian jalan dalam kondisi tertentu (misalnya: rencana geometric, lingkungan, komposisi lalu lintas dan sebagainya [1] (biasanya dinyatakan dalam kend/jam atau smp/jam). Salah satu faktor yang mempengaruhi kapasitas suatu jalan perkotaan adalah keberadaan pasar baik pasar tardisonal maupun pasar modern.

Pasar adalah satu dari berbagai sistem, institusi, prosedur, hubungan sosial dan infrastruktur dimana usaha menjual barang, jasa dan tenaga kerja untuk orang - orang dengan imbalan uang [2]. Pasar juga merupakan sekumpulan orang yang memiliki keinginan untuk puas, uang yang digunakan untuk 
berbelanja dan memiliki kemauan untuk membelanjakan uang [3]. Sebagian pasar - pasar yang ada sudah dilakukan pembaharuan, yang tadinya masih berupa pasar tradisional, sekarang sudah direhap dan diperbaharui oleh pemerintah menjadi pasar - pasar semi modern dan bahkan menjadi pasar modern. Tetapi belum semua dapat diubah menjadi pasar modern, salah satunya adalah pasar Teratai yang terletak di Jalan Komyos Sudarso Pontianak. Pasar ini masih merupakan pasar tradisional yang dimanfaatkan oleh masyarakat sekitarnya untuk melakukan transaksi jual beli. Keadaan pasar rakyat ini begitu dipadati oleh masyarakat sekitar lokasi. Kondisi dari pasar ini sendiri masih belum tertata dengan baik, masih terlihat kesemrautan yang dapat berakibat pada terganggunya pengguna jalan. Belum adanya fasilitas parkir yang memadai sehingga kendaraan menggunakan badan jalan untuk menempatkan kendaraannya yang akan berakibat terjadinya kemacetan di jalan. Padahal Jalan Komyos Sudarso Pontianak merupakan jalan perkotaan. Mengingat kondisi yang seperti ini peneliti ingin meninjau lebih dalam mengenai aktifitas pasar yang mempengaruhi kapasitas jalan Komyos Sudarso, mengetahui besaran hambatan samping yang akan terdata dari hasil survei di Pasar Teratai jalan Komyos Sudarso, serta mengetahui kinerja jalan Komyos Sudarso pada segmen Pasar Teratai [4].

\section{Metode Penelitian}

a. Pengumpulan Data diperoleh dari survei dan pengamatan langsung di lapangan [5]. Adapun teknik pengumpulan data yang digunakan dalam penelitian ini dengan observasi, dimana peneliti melakukan peninjauan langsung ke lokasi yang akan dijadikan objek penelitian. Data yang diambil diantaranya data volume lalu lintas. Data volume lalu lintas kendaraan yang diambil adalah kendaraan yang melewati pos pengamatan yang dibedakan dalam beberapa jenis kendaraan.

b. Persiapan survei yang harus dilakukan adalah menyiapkan formulir untuk mempermudahkan pelaksanaan survei, menyiapkan alat tulis dengan petunjuk waktu, menyiapkan alat hand tally counter dan alat komunikasi [6]. Kemudian menyiapkan personil survei, membagikan tugas-tugas kepada surveyor, dan melatih para surveyor agar tidak kebingungan pada saat melakukan tugastugasnya.

c. Waktu survei untuk pengambilan data volume lalu lintas dilakukan selama empat hari (Jum'at, Sabtu, Minggu, Kamis) dimulai dari pukul 06.00 - 18.00 WIB atau selama 12 jam setiap hari [7]. Posisi petugas pencatat ditempatkan ditepi jalan agar mudah untuk mengamati pergerakan lalu lintas/kendaraan yang melewati jalan yang diteliti dan juga terhindar dari pengaruh cuaca (panas matahari/hujan). Disetiap pos pencatat tersebut surveyor masing-masing dilengkapi dengan perlengkapan seperti formulir isian, alat tulis, alat komunikasi dan petunjuk waktu/jam. Semua data diperoleh dimasukan kedalam formulir yang telah disediakan.

d. Survei hambatan samping dengan cara terjun langsung kelokasi yang ditinjau [8]. Data yang diperoleh dengan cara mencatat hambatan samping yang berpengaruh terhadap kapasitas dan kinerja jalan yang ada dilokasi peninjauan [9]. Untuk mengetahui kelas hambatan samping pada lokasi tinjauan, perlu dilakukan survei hambatan samping dengan menghitung kendaraan yang parkir atau berhenti disepanjang daerah pengamatan yang mengganggu arus lalu lintas, kendaraan yang masuk dan keluar dari samping jalan pengamatan, kendaraan lambat/kendaraan tak bermotor yang dilewati daerah pengamatan dan pejalan kaki yang mengganggu arus lalu lintas [10].

e. Survei geometrik jalan untuk mendapatkan data geometrik jalan seperti lebar badan jalan, jumlah lajur dan lebar bahu jalan [11]. Metode yang dipakai pada survei ini adalah mengadakan pengukuran langsung dilapangan/lokasi penelitian. Pengukuran geometrik dilakukan dengan menggunakan meteran dan waktu dilakukan survei pada saat lalu lintas sepi (malam atau subuh) agar tidak mengganggu lalu lintas jalan.

\section{Hasil dan Pembahasan \\ Pasar Teratai}

Pasar Teratai terletak di Jalan KomYos Sudarso Pontianak yang sudah berdiri sejak Tahun 1982. Pasar ini berdiri diatas tanah seluas $2941 \mathrm{~m}^{2}$. Bangunan pasar terdiri dari 2 lantai dimana terdapat 189 Los dan 204 kios. Semakin lama aktifitas pasar semakin meningkat sehingga pemerintah merenovasi dan membangun kembali bangunan pasar menjadi bangunan permanen. Bangunan baru Pasar Teratai ini diresmikan oleh Walikota tahun 2012. Pasar Teratai menyediakan area parkir untuk sepeda motor berkisar 200 unit tanpa adanya area parkir mobil.

\section{Analisa Volume Lalu Lintas}

Data volume Lalu Lintas Jalan Komyos Sudarso untuk segmen pasar Teratai didapat dari hasil lalu lintas yang dilaksanakan selama empat hari berturut-turut pada Tanggal 19 November sampai 22 
November 2020 yang meliputi hari-hari yang mewakili (Kamis, Jumat, Sabtu dan Minggu) pada jam 06.00-18.00 atau selama 12 jam.

a. Volume Lalu Lintas Harian

$\underline{\text { Tabel 1. Volume lalu lintas hasil survei di lapangan dalam satuan kend/jam pada hari Kamis dan Jumat }}$

\begin{tabular}{|c|c|c|c|c|c|c|c|}
\hline \multirow[t]{2}{*}{ No. } & \multirow[t]{2}{*}{ Waktu } & \multicolumn{3}{|c|}{$\begin{array}{c}\text { Kamis } \\
\text { Kend/jam }\end{array}$} & \multicolumn{3}{|c|}{$\begin{array}{c}\text { Jum'at } \\
\text { Kend/jam }\end{array}$} \\
\hline & & LV & $\mathrm{HV}$ & MC & LV & $\mathrm{HV}$ & MC \\
\hline 1. & $06.00-07.00$ & 79 & 16 & 1573 & 69 & 14 & 1374 \\
\hline 2. & $07.00-08.00$ & 242 & 27 & 1908 & 209 & 21 & 1869 \\
\hline 3. & $08.00-09.00$ & 360 & 49 & 2593 & 352 & 53 & 3060 \\
\hline 4. & $09.00-10.00$ & 239 & 37 & 1778 & 246 & 31 & 1256 \\
\hline 5. & $10.00-11.00$ & 329 & 48 & 2220 & 172 & 27 & 1862 \\
\hline 6. & $11.00-12.00$ & 370 & 62 & 2029 & 218 & 21 & 1734 \\
\hline 7. & $12.00-13.00$ & 348 & 39 & 2031 & 207 & 26 & 1883 \\
\hline 8. & $13.00-14.00$ & 442 & 56 & 2316 & 264 & 37 & 1840 \\
\hline 9. & $14.00-15.00$ & 287 & 91 & 1156 & 371 & 49 & 2883 \\
\hline 10. & $15.00-16.00$ & 378 & 61 & 1250 & 345 & 57 & 3271 \\
\hline 11. & $16.00-17.00$ & 480 & 78 & 4027 & 495 & 63 & 6022 \\
\hline 12. & $17.00-18.00$ & 461 & 48 & 2530 & 467 & 44 & 5872 \\
\hline Total & & 4015 & 612 & 25411 & 3415 & 443 & 32926 \\
\hline
\end{tabular}

Tabel 2. Volume lalu lintas hasil survei di lapangan dalam satuan kend/jam Pada Hari Sabtu dan Minggu

\begin{tabular}{cccccccc}
\hline \multirow{2}{*}{ No. } & \multirow{3}{*}{ Waktu } & \multicolumn{3}{c}{$\begin{array}{c}\text { Kabtu } \\
\text { Kend/jam }\end{array}$} & \multicolumn{3}{c}{$\begin{array}{c}\text { Minggu } \\
\text { Kend/jam }\end{array}$} \\
\cline { 3 - 8 } & & LV & HV & MC & LV & HV & MC \\
\hline 1. & $06.00-07.00$ & 142 & 32 & 2573 & 198 & 12 & 3472 \\
2. & $07.00-08.00$ & 252 & 52 & 3863 & 163 & 9 & 2173 \\
3. & $08.00-09.00$ & 357 & 47 & 4113 & 259 & 14 & 2421 \\
4. & $09.00-10.00$ & 341 & 67 & 2884 & 271 & 21 & 2119 \\
5. & $10.00-11.00$ & 271 & 42 & 1967 & 254 & 23 & 3111 \\
6. & $11.00-12.00$ & 242 & 31 & 1723 & 269 & 26 & 2113 \\
7. & $12.00-13.00$ & 261 & 39 & 1421 & 251 & 17 & 2026 \\
8. & $13.00-14.00$ & 497 & 73 & 1839 & 142 & 15 & 1884 \\
9. & $14.00-15.00$ & 295 & 92 & 1729 & 277 & 31 & 2236 \\
10. & $15.00-16.00$ & 424 & 86 & 3630 & 416 & 54 & 3429 \\
11. & $16.00-17.00$ & 895 & 63 & 6837 & 713 & 37 & 4513 \\
12. & $17.00-18.00$ & 777 & 23 & 6639 & 576 & 29 & 4527 \\
\hline Total & \multicolumn{7}{c}{ Sumber: Hasil survey (2020) } \\
\hline
\end{tabular}

Tabel 3. Lalu lintas Harian Rata-rata (LHR) dalam satuan smp/jam pada hari Kamis dan Jumat

\begin{tabular}{cccccccc}
\hline \multirow{2}{*}{ No. } & \multirow{2}{*}{ Waktu } & \multicolumn{3}{c}{$\begin{array}{c}\text { Kamis } \\
\text { Smp/jam }\end{array}$} & \multicolumn{3}{c}{$\begin{array}{c}\text { Jum'at } \\
\text { Smp/jam }\end{array}$} \\
\cline { 3 - 8 } & & LV & HV & MC & LV & HV & MC \\
\hline 1. & $06.00-07.00$ & 79 & 19 & 393 & 69 & 17 & 344 \\
2. & $07.00-08.00$ & 242 & 32 & 477 & 209 & 25 & 467 \\
3. & $08.00-09.00$ & 360 & 59 & 648 & 352 & 64 & 765 \\
4. & $09.00-10.00$ & 239 & 44 & 445 & 246 & 37 & 314 \\
5. & $10.00-11.00$ & 329 & 58 & 555 & 172 & 32 & 466 \\
6. & $11.00-12.00$ & 370 & 74 & 507 & 218 & 25 & 434 \\
7. & $12.00-13.00$ & 348 & 47 & 508 & 207 & 31 & 471 \\
8. & $13.00-14.00$ & 442 & 67 & 579 & 264 & 44 & 460 \\
9. & $14.00-15.00$ & 287 & 109 & 289 & 371 & 59 & 721 \\
10. & $15.00-16.00$ & 378 & 73 & 313 & 345 & 68 & 818 \\
11. & $16.00-17.00$ & 480 & 94 & 1007 & 495 & 76 & 1506 \\
12. & $17.00-18.00$ & 461 & 58 & 633 & 467 & 53 & 1468 \\
\hline Total & \multicolumn{7}{c}{ Sumber: Hasil survey $(2020)$} \\
\hline
\end{tabular}


Tabel 4. Lalu lintas Harian Rata-rata (LHR) dalam satuan smp/jam Pada Hari Sabtu dan Minggu

\begin{tabular}{|c|c|c|c|c|c|c|c|}
\hline \multirow[t]{2}{*}{ No. } & \multirow[t]{2}{*}{ Waktu } & \multicolumn{3}{|c|}{$\begin{array}{c}\text { Sabtu } \\
\text { Smp/jam }\end{array}$} & \multicolumn{3}{|c|}{$\begin{array}{l}\text { Minggu } \\
\text { Smp/jam }\end{array}$} \\
\hline & & $\mathrm{LV}$ & $\mathrm{HV}$ & $\mathrm{MC}$ & LV & $\mathrm{HV}$ & $\mathrm{MC}$ \\
\hline 1 & $06.00-07.00$ & 142 & 38 & 643 & 198 & 14 & 868 \\
\hline 2 & $07.00-08.00$ & 252 & 62 & 966 & 163 & 11 & 543 \\
\hline 3 & 08.00-09.00 & 357 & 56 & 1028 & 259 & 17 & 605 \\
\hline 4 & $09.00-10.00$ & 341 & 80 & 721 & 271 & 25 & 530 \\
\hline 5 & $10.00-11.00$ & 271 & 50 & 492 & 254 & 28 & 778 \\
\hline 6 & $11.00-12.00$ & 242 & 37 & 431 & 269 & 31 & 528 \\
\hline 7 & $12.00-13.00$ & 261 & 47 & 355 & 251 & 20 & 507 \\
\hline 8 & $13.00-14.00$ & 497 & 88 & 460 & 142 & 18 & 471 \\
\hline 9 & $14.00-15.00$ & 295 & 110 & 432 & 277 & 37 & 559 \\
\hline 10 & $15.00-16.00$ & 424 & 103 & 908 & 416 & 65 & 857 \\
\hline 11 & $16.00-17.00$ & 895 & 76 & 1709 & 713 & 44 & 1128 \\
\hline 12 & $17.00-18.00$ & 777 & 28 & 1660 & 576 & 35 & 1132 \\
\hline Total & & 4754 & 776 & 9805 & 3789 & 346 & 8506 \\
\hline
\end{tabular}

Sumber: Hasil survey (2020)

Tabel 5. Total volume lalulintas dan lalu lintas harian rata-rata (LHR)

\begin{tabular}{|c|c|c|c|c|c|c|c|c|c|}
\hline \multirow[t]{2}{*}{ No. } & \multirow[t]{2}{*}{ Waktu } & \multicolumn{4}{|c|}{$\begin{array}{c}\text { Total Jumlah Kendaraan } \\
\text { Kend/Jam }\end{array}$} & \multicolumn{4}{|c|}{$\begin{array}{c}\text { Total Jumlah Kendaraan } \\
\text { Smp/Jam }\end{array}$} \\
\hline & & Kamis & Jum'at & Sabtu & Minggu & Kamis & Jum'at & Sabtu & Minggu \\
\hline 1 & $06.00-07.00$ & 1668 & 1457 & 2747 & 3682 & 491 & 429 & 824 & 1080 \\
\hline 2 & $07.00-08.00$ & 2177 & 2099 & 4167 & 2345 & 751 & 701 & 1280 & 717 \\
\hline 3 & 08.00-09.00 & 3002 & 3465 & 4517 & 2694 & 1067 & 1181 & 1442 & 881 \\
\hline 4 & $09.00-10.00$ & 2054 & 1533 & 3292 & 2411 & 728 & 597 & 1142 & 826 \\
\hline 5 & $10.00-11.00$ & 2597 & 2061 & 2280 & 3388 & 942 & 670 & 813 & 1059 \\
\hline 6 & $11.00-12.00$ & 2461 & 1973 & 1996 & 2408 & 952 & 677 & 710 & 828 \\
\hline 7 & $12.00-13.00$ & 2418 & 2116 & 1721 & 2294 & 903 & 709 & 663 & 778 \\
\hline 8 & $13.00-14.00$ & 2814 & 2141 & 2409 & 2041 & 1088 & 768 & 1044 & 631 \\
\hline 9 & $14.00-15.00$ & 1534 & 3303 & 2116 & 2544 & 685 & 1151 & 838 & 873 \\
\hline 10 & $15.00-16.00$ & 1689 & 3673 & 4140 & 3899 & 764 & 1231 & 1435 & 1338 \\
\hline 11 & $16.00-17.00$ & 4585 & 6580 & 7795 & 5263 & 1580 & 2076 & 2680 & 1886 \\
\hline 12 & $17.00-18.00$ & 3039 & 6383 & 7439 & 5132 & 1151 & 1988 & 2464 & 1743 \\
\hline Total & & 30038 & 36784 & 44619 & 38101 & 11102 & 12178 & 15335 & 12641 \\
\hline
\end{tabular}

b. Volume Lalu Lintas Mingguan (LMR)

Dari jumlah lalu lintas selama 12 jam perhari dalam satu minggu yang dikalikan dengan faktor koreksi (93\%), maka dapat ditentukan lalu lintas mingguan rata-rata (LMR). Dari hasil survei diperoleh jumlah kendaraan selama 12 jam selama 4 hari dengan rumus:

Dimana:

$$
\frac{(4 W+X+Y+Z)}{\frac{(7 \times 100)}{93}}
$$

W : Data survey hari Senin - Kamis

$\mathrm{X}$ : Data Survey hari Jum'at

Y : Data survey hari Sabtu

Z : Data survey hari Minggu

Perhitungan volume lalu lintas jalan Komyos Sudarso mingguan rata-rata (LMR):

Perhitungan Volume Lalu Lintas Jalan Komyos Sudarso Mingguan Rata-Rata (LMR)

LMR Kendaraan Ringan :

$((4 \times 11102)+12178+15335+12641) / 7 \times 100 / 93=12990$

c. Volume Lalu Lintas Harian Rata Rata Tahunan (LHRT)

Setelah menghitung volume mingguan (LMR) selanjutnya dihitung volume lalu lintas bulanan ratarata (LBR). [12] menjelaskan bahwa persentase LBR dalam setahun yang berguna untuk mendapatkan 
data lalu lintas dalam setahun (LRT) [12], dengan menggunakan Tabel 6 yang memperlihatkan faktor presentase lalu lintas bulanan setahun pada bulan November adalah 96\% dari Lalu Lintas Harian RataRata Tahunan.

Tabel 6. LBR sebagai persentase lalu lintas bulanan setahun

\begin{tabular}{ccc}
\hline Bulan & Kota & Desa \\
\hline Januari & 81 & 71 \\
Februari & 89 & 77 \\
Maret & 94 & 86 \\
April & 99 & 97 \\
Mei & 104 & 107 \\
Juni & 110 & 121 \\
Juli & 111 & 127 \\
Agustus & 112 & 136 \\
September & 109 & 117 \\
Oktober & 102 & 96 \\
November & 96 & 85 \\
Desember & 92 & 79 \\
\hline
\end{tabular}

Sumber: Hasil perhitungan (2020)

Perhitungan lalu lintas rata-rata tahunan (LHRT) sebagai berikut :

LHRT kendaraan ringan $=\mathrm{LMR} \times 100 / 96 \%$

$=12990 \times 100 / 96=13531$

d. Volume Jam Perencana (VJP)

Volume jam perencana (VJP), lalu lintas yang digunakan adalah dalam bentuk volume smp/jam. Adapun perhitungan arus lalu lintas untuk desain dapat diestimasikan dari AADT sebagai berikut:

$\mathrm{Q}=\mathrm{AADT} \times \mathrm{K}$

Dimana :

$\mathrm{K} \quad$ : Nilai normal variabel lalu lintas umum berkisar 0.07-0.12

AADT : Averge Annual Daily Traffic atau LHRT

Tabel 7. Nilai normal faktor K

\begin{tabular}{lcc}
\hline \multirow{2}{*}{ Lingkungan Jalan } & \multicolumn{2}{c}{ Faktor Ukuran Kota } \\
\cline { 2 - 3 } & $>$ 1 JUTA & $<$ 1 JUTA \\
\hline Jalan Pada daerah komersial dan arteri & $0.07-0.08$ & $0.08-0.10$ \\
Jalan pada daerah pemukiman & $0.08-0.09$ & $0.09-0.12$ \\
\hline \multicolumn{2}{c}{ Sumber: MKJI (1997) }
\end{tabular}

Dalam penelitian ini faktor nilai ukuran kota diambil 0.08 sehingga perhitungan Volume Jam Perencanaan (VJP) untuk masing - masing kendaraan [13] adalah :

$$
\begin{array}{ll}
\text { Q Kendaraan Ringan } & \text { AADT } \times 0.08 \\
& 13531 \times 0.08=1082 \mathrm{smp} / \mathrm{jam}
\end{array}
$$

Tabel 8. Hasil perhitungan LMR, LHRT, VJP 2020

\begin{tabular}{cccc}
\hline \multirow{2}{*}{ Lokasi } & $\begin{array}{c}\text { LMR 2020 } \\
\text { (Kend/hari) }\end{array}$ & $\begin{array}{c}\text { LHRT 2020 } \\
(\text { Kend/hari })\end{array}$ & $\begin{array}{r}\text { VJP 2020 } \\
\text { (Kend/hari) }\end{array}$ \\
\cline { 2 - 4 } & $\begin{array}{c}\text { Kendaraan } \\
\text { Ringan }\end{array}$ & $\begin{array}{c}\text { Kendaraan } \\
\text { Ringan }\end{array}$ & Total \\
\hline $\begin{array}{c}\text { Segmen Pasar Terata } \\
\text { (Jalan Komyos Sudarso) }\end{array}$ & 12990 & 13531 & 1082 \\
\hline
\end{tabular}

Sumber: Hasil perhitungan (2020) 


\section{Kelas Hambatan Samping}

Kelas hambatan samping yang dapat dilihat langsung terhadap kondisi sesungguhnya dari segmen pasar Teratai menunjukkan bahwa kelas hambatan samping termasuk dalam kelas yang tinggi saat beroperasinya pasar. Hasil pengamatan dapat disimpulkan dengan melihat Tabel 9 dan Tabel 10, pada jam-jam beroperasinya pasar terlihat hambatan samping yang rata - rata tinggi untuk jalan Komyos Sudarso. Kendaraan-kendaraan banyak yang memanfaatkan badan jalan untuk meletakkan kendaraan mereka saat melakukan aktifitas pasar yaitu berbelanja.

Tabel 9. Kelas hambatan samping untuk Jalan Komyos Sudarso Pasar Teratai pada hari Kamis dan Jumat

\begin{tabular}{|c|c|c|c|c|}
\hline \multirow[b]{2}{*}{ Waktu } & \multicolumn{2}{|c|}{ Kamis } & \multicolumn{2}{|r|}{ Jumat } \\
\hline & $\begin{array}{c}\text { Hambatan } \\
\text { Samping }\end{array}$ & $\begin{array}{c}\text { Kelas } \\
\text { Hambatan } \\
\text { Samping }\end{array}$ & $\begin{array}{c}\text { Hambatan } \\
\text { Samping }\end{array}$ & Kelas Hambatan Samping \\
\hline $06.00-07.00$ & 261,6 & Rendah & 457 & Sedang \\
\hline $07.00-08.00$ & 504,9 & Tinggi & 645,2 & Tinggi \\
\hline 08.00-09.00 & 502,5 & Tinggi & 605,2 & Tinggi \\
\hline 09.00-10.00 & 502 & Tinggi & 591,8 & Tinggi \\
\hline $10.00-11.00$ & 342,1 & Sedang & 455,1 & Sedang \\
\hline $11.00-12.00$ & 273,8 & Rendah & 295,7 & Rendah \\
\hline $12.00-13.00$ & 220,4 & Rendah & 364,7 & Sedang \\
\hline $13.00-14.00$ & 399,4 & Sedang & 267,8 & Rendah \\
\hline $14.00-15.00$ & 319,4 & Sedang & 545,3 & Tinggi \\
\hline $15.00-16.00$ & 449,1 & Sedang & 585 & Tinggi \\
\hline $16.00-17.00$ & 557,3 & Tinggi & 741,3 & Tinggi \\
\hline $17.00-18.00$ & 428,7 & Sedang & 612,7 & Tinggi \\
\hline
\end{tabular}

Sumber : Hasil perhitungan (2020)

Tabel 10. Kelas hambatan samping untuk Jalan Komyos Sudarso Pasar Teratai pada hari Sabtu dan Minggu

\begin{tabular}{cccccc}
\hline \multirow{2}{*}{ Waktu } & \multicolumn{3}{c}{ Sabtu } & \multicolumn{2}{c}{ Minggu } \\
& \multicolumn{1}{c}{$\begin{array}{c}\text { Hambatan } \\
\text { Samping }\end{array}$} & $\begin{array}{c}\text { Kelas Hambatan } \\
\text { Samping }\end{array}$ & $\begin{array}{c}\text { Hambatan } \\
\text { Samping }\end{array}$ & $\begin{array}{c}\text { Kelas Hambatan } \\
\text { Samping }\end{array}$ & $\begin{array}{c}\text { Rata-Rata } \\
\text { (Kamis-Minggu) }\end{array}$ \\
\hline $06.00-07.00$ & 675,7 & Tinggi & 866,8 & Tinggi & 565,27 \\
$07.00-08.00$ & 611,4 & Tinggi & 753 & Tinggi & 628,62 \\
$08.00-09.00$ & 708 & Tinggi & 902 & Sangat Tinggi & 679,42 \\
$09.00-10.00$ & 711,5 & Tinggi & 862,8 & Tinggi & 667,0 \\
$10.00-11.00$ & 722,7 & Tinggi & 450,8 & Sedang & 492,67 \\
$11.00-12.00$ & 378,7 & Sedang & 428,1 & Sedang & 344,07 \\
$12.00-13.00$ & 283 & Rendah & 392,9 & Sedang & 315,25 \\
$13.00-14.00$ & 282,8 & Rendah & 281,2 & Rendah & 307,8 \\
$14.00-15.00$ & 381,6 & Sedang & 479,6 & Sedang & 431,47 \\
$15.00-16.00$ & 511,9 & Tinggi & 508,2 & Tinggi & 513,55 \\
$16.00-17.00$ & 645,2 & Tinggi & 541,1 & Tinggi & 621,225 \\
$17.00-18.00$ & 557 & Tinggi & 534,4 & Tinggi & 533,2 \\
\hline
\end{tabular}

Sumber : Hasil perhitungan (2020)

Frekuensi bobot hambatan samping rata-rata harian untuk segmen Pasar Teratai didapat dari total frekuensi hambatan samping rata-rata harian dibagi dengan lamanya survei dalam satu hari, didapatkan:

$$
\text { Frekuensi bobot }=6099,6 / 12=508,3
$$

Dengan demikian dapat diketahui bahwa untuk segmen pasar Teratai mempunyai kelas hambatan samping yang tinggi dengan kode $\mathrm{H}$ yaitu 508,3 kondisi khusus daerah komersial; aktifitas sisi jalan tinggi [14].

\section{Analisa Kinerja Existing}

1. Perhitungan Kapasitas dan Kinerja Jalan Komyos Sudarso Segmen Pasar Teratai

Untuk mengetahui tingkat kinerja lalu lintas Jalan Komyos Sudarso segmen pasar Teratai pada tahun 2020 maka perhitungannya sebagai berikut: 
-Volume Jam Perencanaan

$Q=1082^{\mathrm{smp}} /$ jam

$\mathrm{SP}=50 \%-50 \%$

- Kapasitas Jalan

Co : $2900 \mathrm{smp} /$ jam kapasitas dasar perlajur untuk 2/2 UD

FCw : 1,34 $\mathrm{Wc}=11 \mathrm{~m}$ pada $2 / 2 \mathrm{UD}$

FCsp : 1.00 untuk $\mathrm{SP}=50 \%-50 \%$ pada $2 / 2 \mathrm{UD}$

FCsf : $0.86 \mathrm{Wk}=1 \mathrm{~m}$ dan kelas hambatan samping $\mathrm{H}$ pada $2 / 2 \mathrm{UD}$

FCcs : 0.94 untuk ukuran kota berpenduduk 0,5 - 1,0 juta jiwa [15]

$$
\begin{gathered}
C=\mathrm{Co} \times \mathrm{FCw} \times \mathrm{FCsp} \times \mathrm{FCsf} \times \mathrm{FCcs} \\
C=2900 \times 1,34 \times 1,00 \times 0,86 \times 0,94 \\
C=3141^{\mathrm{smp} / j a m}
\end{gathered}
$$

Tabel 11. Nilai kapasitas Jalan Segmen Pasar Teratai

\begin{tabular}{ccccccc}
\hline & Co & FCw & FCsp & FCsf & FCcs & C \\
\hline Nilai & 2900 & 1,34 & 1 & 0,86 & 0,94 & 3141 \\
\hline \multicolumn{7}{c}{ Sumber : Hasil perhitungan $(2020)$}
\end{tabular}

- Derajat Kejenuhan (DS)

$$
D S=\frac{Q}{C}=\frac{1082}{3141}=0,34
$$

- Kecepatan Arus Bebas

$$
F V=\left(F V_{0}+F V_{w}\right) \times F F V_{s f} \times F F V_{c s}
$$

$\mathrm{FVo}=44 \mathrm{~km} / \mathrm{jam}$ (untuk kendaraan ringan pada $2 / 2 \mathrm{UD}$ )

$\mathrm{FVw}=7 \mathrm{~km} / \mathrm{jam}$ (untuk kendaraan ringan pada $2 / 2 \mathrm{UD}$ )

FFVsf $=0,86$ (untuk Wk $=1.0 \mathrm{~m}$, kelas hambatan samping $\mathrm{H}$ pada $2 / 2 \mathrm{UD}$ )

FFVes $=0,95$ (untuk jalan 2/2 UD pada kota berpenduduk 0,5-1,0 juta jiwa)

$$
\begin{gathered}
F V=(44+7) \times 0,86 \times 0,95 \\
F V=41,67 \mathrm{~km} / \mathrm{jam}
\end{gathered}
$$

Tabel 12. Nilai kecepatan arus bebas segmen Pasar Teratai

\begin{tabular}{cccccc}
\hline & FVo & FVw & FFVsf & FFVcs & FV \\
\hline Nilai & 44 & 7 & 0,86 & 0,95 & 42 \\
\hline \multicolumn{5}{c}{ Sumber: Hasil perhitungan (2020) }
\end{tabular}

$\mathrm{FV}_{\mathrm{LV}}$ yang didapat adalah $37 \mathrm{~km} / \mathrm{jam}$ (berdasarkan grafik untuk DS = 0,34 dan $\mathrm{FV}=42 \mathrm{~km} / \mathrm{jam}$ ), maka arus lalu lintas masih dikategorikan cukup stabil, hal ini dapat dilihat pada Gambar 1.

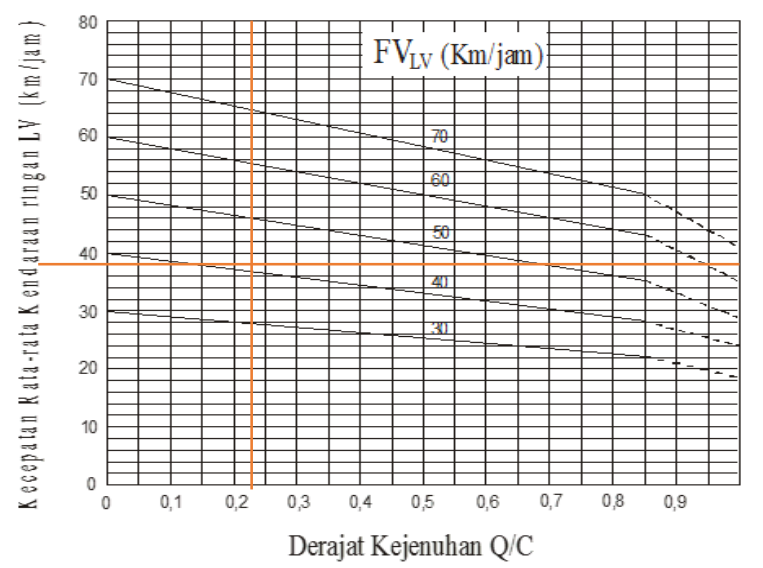

Gambar 1. Kecepatan sebagai fungsi DS Untuk Jalan 2/2 UD Sumber: Hasil analisa (2020) 


\section{Kesimpulan}

Aktifitas pasar yang terletak di tepi jalan utama seperti Jalan Komyos Sudarso yaitu Pasar Teratai sangat berpengaruh besar terhadap kapasitas jalan. Arus lalu lintas menjadi meningkat di saat beroperasinya pasar. Survey hambatan samping menghasilkan kelas untuk hambatan samping di jalan Komyos Sudarso segmen pasar Teratai. Hambatan samping yang diamatai adalah kendaraan yang masuk dan keluar dari samping jalan pengamatan, kendaraan lambat, pejalan kaki serta kendaraan yang parkir atau berhenti di sepanjang daerah pengamatan. Dengan kapasitas ruang parkir yang tidak memadai di kawasan pasar yang hanya diperuntukkan untuk kendaraan bermotor saja, mengakibatkan banyak pengguna kendaraan memarkirkan kendaraannya di badan jalan. Kelas hambatan samping untuk kawasan ini termasuk kelas yang tinggi $(\mathrm{H})$ dengan frekuensi bobot 508,3. Kinerja jalan Komyos Sudarso dari hasil hitungan memperlihatkan angkanya masih dibawah ambang batas jenuhnya yaitu masing diangka 0,34. Ini menandakan arus lalu lintas masih cukup stabil untuk dilalui oleh kendaraan dan memperoleh kecepatan rata-rata kendaraan ringan yang masih di angka $37 \mathrm{~km} / \mathrm{jam}$.Untuk kedepannya di dalam penataan daerah komersial dengan aktifitas sisi jalan yang tinggi pasar perlu dibuat area parkir yang optimal bagi pengguna kendaraan, baik kendaraan bermotor maupun kendaraan roda empat.

\section{Referensi}

[1] Manual Kapasitas Jalan Indonesia, "MKJI”, Direktorat Jenderal Bina Marga, Direktorat Bina Jalan Kota (Binkot). P. T Bina Karya (Persero), 1997.

[2] M. Fuad, Christine, H., Nurlela, Sugiarto, Paulus, YFE., "Pengantar Bisnis" , PT. Gramedia Pustaka Utama, Jakarta, 2006.

[3] Stanson William J, Yohanes Lamarto, "Prinsip Pemasaran”, Erlangga, Jakarta, 1993.

[4] Randy Syaputra, Syukur Sebayang, Dwi Heriyanto, "Pengaruh Hambatan Samping Terhadap Kinerja Lalu Lintas Jalan Nasional (Studi Kasus Jalan Proklamator Raya - Pasar Banjarjaya Plaza))", Journal Rekayasa Sipil dan Desain Universitas Lampung, Vol.3, No.3, 2015.

[5] Adrianus Gusti Andri Darmawan, Syafarudiin AS, Rudi Sugiono Suyono, " Dampak Pembangunan Jembatan Kapuas I (Paralel) Terhadap Kinerja Simpang Bersinyal Kota Pontianak", Jurnal Mahasiswa Teknik Sipil Universitas Tanjungpura, Vol 5, No.3, 2018.

[6] Edo Novaldi Almaut, Syafaruddin AS, Siti Nurlaily Kadarini, "Analisa Kapasitas Dan Kinerja Ruas Jalan Perintis Kemerdekaa Pontianak", Jurnal Mahasiswa Teknik Sipil Universitas Tanjungpura, Vol 3, No. 3, 2016.

[7] Alhani, Komala Erwan, Eti Sulandari, "Analisia Lalu lintas terhadap Kapasitas Jalan di Pinggiran Pontianak (Kasus Jalan Sungai Raya Dalam)”, Jurnal Mahasiswa Teknik Sipil Universitas Tanjungpura, Vol 4. No 4, 2017.

[8] R. Restu Destiyanto, Slamet Widodo, Eti Sulandari, “Analisis Kinerja Lalu Lintas Di Jembatan Landak", Vol 2, No. 2, 2016

[9] Rizani, Ahmad, 2013, Evaluasi Kinerja Jalan Akibat Hambatan Samping, ITB, Bandung.

[10] U.Winda Dwi Septia, "Analisis Kinerja Jalan Komyos Sudarso Pontianak", Jurnal Teknik Sipil Universitas Tanjungpura, Vol 13. No 2, 2013.

[11] WA Dinata, Komala Erwan, Sumiyattinah, "Analisis Kinerja Simpang Tiga pada Jalan Komyos Sudarso - Jalan Umuthalib Kota Pontianak", Jurnal Mahasiswa Teknik Sipil Universitas Tanjungpura, Vol 4. No 4, 2017.

[12] Wells, G.R., 1993, Rekayasa Lalu Lintas, Penerjemah Ir. Suwardjoko Warpani, Jakarta, Bhrata.

[13] Budi Siswanto, Syafaruddin AS, Eti Sulandari, “ Pengaruh Pembangunan Kawasan Perdagangan Terhadap Lalu Lintas Di Jembatan Landak (Ruko Anggrek Pontianak J1. Sultan Hamid II)”,Jurnal Mahasiswa Teknik Sipil Universitas Tanjungpura, Vol 1, No. 1, 2016.

[14] Angga PrialiadiSaldi, Syafaruddin AS, S. Nurlaily Kadarini, “ Analisa Kinerja Ruas Jalan Imam Bonjol Dan Simpang Jalan Imam Bonjol - Jalan Daya Nasional Di Kota Pontianak", Jurnal Mahasiswa Teknik Sipil Universitas Tanjungpura, Vol 5, No. 3, 2018.

[15] Hendra Masudi, Abubakar Alwi, R.M. Rustamaji, "Kajian Tingkat Kejenuhan Lalu Lintas Pada Jembatan Kapuas I Pontianak", Jurnal Mahasiswa Teknik Sipil Universitas Tanjungpura, Vol 17, No. 1, 2017. 